\title{
Um lixão sob o ponto de vista da geofísica rasa, município de Caracaraí, Roraima, Brasil
}

\author{
Caracaraí's open dump and shallow geophysics, Roraima, northern Brazil
}

\author{
SOUZA $^{1}$, L. S.; ANDRADE 2 , G. G.; $\operatorname{MORAES}^{3}$, G. R.
}

lenabarata@yahoo.com.br;

\begin{abstract}
Resumo
No lixão do município de Caracaraí/RR foi aplicada a técnica da Sondagem Elétrica vertical, com o objetivo de modelar o comportamento geoelétrico da possível contaminação resultante da decomposição dos resíduos sólidos alocados na superfície do terreno. A zona contaminada está na porção central do lixão. As faixas condutivas com $589<\rho_{\mathrm{a}}<179 \Omega$.m foram caracterizadas como indícios de contaminantes. A contaminação é pontual e se concentra primordialmente nas adjacências e sobre a cava. Nas profundidades superficiais a contaminação é mais concentrada em função do nível do lençol freático raso, com apenas $2 \mathrm{~m}$ de profundidade, permitindo a sua maior concentração pontual e migração

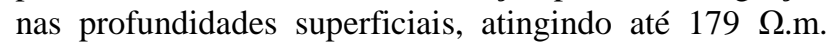
Nas profundidades de 5,5; 7,5 e $24 \mathrm{~m}$ foram localizados alguns pontos com resquícios de contaminantes com valores de resistividades entre $589<\rho_{\mathrm{a}}<322 \Omega$.m. A migração dos contaminantes tendem a ser pontuais e verticais, a pluma não se espraia lateralmente e tende a migrar pontualmente e verticalmente segundo um gradiente gravitacional.
\end{abstract}

Palavras-chave: geoelétrico; resíduos sólidos; Caracaraí.

\begin{abstract}
Ten Vertical Eletric Sounding were held on in the city of Caracaraí (state of Roraima, Northern Brazil) in the portion where entire solid domestic waste of the city is placed. Once the service was carried out, the ten souding had allow us to modelate the geoeletrical behaviour of the plausible area of contamination associated with the decomposition of the solid waste throughout the underlied subsurface. Horizons with $589<\rho_{\mathrm{a}}<179 \Omega . \mathrm{m}$ was interpreted as probable contaminated horizons. This contaminated portion is located in the central area of the waste-deposition place and apparently could be grouped as spots of contamination, probably more intensified near to the big hole of waste deposition. Near to the surface (up to $2 \mathrm{~m}$ depth), the contamination is more concentrated due to the phreatic water that leads to migration and spot concentration with values of resistivity as lower as 179 $\Omega . \mathrm{m}$. Other interest depths are $5.5 \mathrm{~m}, 7.5 \mathrm{~m}$ and $24.0 \mathrm{~m}$ where the values of resistivity were $589<\rho_{\mathrm{a}}<322 \Omega$.m. In this area, the contaminants tend to migrate centered to points and more vertically than horizontally due to gravity.
\end{abstract}

Keywords: geoelectrical; solid waste; Caracaraí.

\section{INTRODUÇÃO}

A problemática gerada pela gestão dos resíduos sólidos produzidos pela população acompanha a humanidade desde as mais remotas épocas do desenvolvimento social. Porém, o tema relacionado ao acúmulo descomunal e do desafio de alocá-lo da forma mais sustentável possível, teve início no período pós-revolução industrial. Ao passo que o problema se agravou, passou a comprometer a qualidade de vida da sociedade, tornando relevante o seu estudo. Atualmente, um aterro sanitário constitui a técnica mais adequada para o tratamento de resíduos sólidos (Frasson et al. 2001; Silva et al. 2005; Mucelin e Bellini, 2008; Scacabarossi e Périco, 2014; Goes, 2016). 
A Associação Brasileira de Normas Técnicas (ABNT) define por meio da NBR 8.419/1992, NBR 13.896/1997 e NBR 10.004/2004 os aterros sanitários como "Técnica de disposição de resíduos sólidos urbanos no solo, sem causar danos à saúde pública e à sua segurança, minimizando os impactos ambientais. Esta técnica utiliza princípios de engenharia para confinar os resíduos sólidos à menor área possível e reduzi-los ao menor volume permissível, cobrindo-os com uma camada de terra na conclusão de cada jornada de trabalho, ou a intervalos menores, se necessário".

A ausência de um tratamento de solo eficiente em aterros sanitários acarreta na contaminação do meio geológico em profundidade e dos corpos hídricos (superficiais e subterrâneos), impactando profundamente na população que utiliza estes recursos. Segundo Golueke (1974), Schalch (1992), Christensen et al. (2001), Celere et al. (2007) e Portela e Ribeiro (2014) dos contaminantes produzidos pelos aterros, destaca-se o chorume (líquido escuro e de odor desagradável, composto essencialmente por substâncias sulforadas, nitrogenadas e cloradas tóxicas, formadas devido a decomposição bacteriana dos compostos orgânicos, e movimentadas por conta da umidade pertinente ao local). Os períodos chuvosos facilitam a lixiviação do chorume em subsuperfície, percolando entre as rochas porosas e migrando em direção as águas subterrâneas na forma de uma pluma.

A configuração do comportamento e geometria em profundidade do chorume vem sendo amplamente averiguado e discutido desde o final do século XIX (Elis e Zuquette, 2002; Moura e Malagutti Filho, 2003; Gallas et al. 2005; Lago et al. 2006; Moura et al. 2007; Braga, 2007; Bortolin e Malagutti Filho, 2010 e 2012; Falcão et al. 2012; Soares et al. 2016; Souza e Paz, 2018). A ciência geofísica em relação a este tipo de ambiente, mostra-se como alternativa indireta de estudo, permitindo caracterizar subsuperficialmente a interação dos contaminantes com o meio físico. Dentre os métodos geofísicos, os mais utilizados para ambientes contaminados são os métodos elétricos, que consistem em observar como o material geológico em subsuperfície se comporta frente à injeção de corrente elétrica. Esta técnica é bastante útil para o mapeamento de plumas de contaminação, uma vez que os contaminantes facilmente interferem na condutividade dos solos, das rochas e de águas subterrâneas e superficiais.

Desta forma, propôs-se com este trabalho a distinção do comportamento elétrico da possível contaminação advinda do lixão do município de Caracaraí, estado de Roraima, por meio do uso integrado do método elétrico (Levantamento Eletrorresistivo-ER com uso da técnica de Sondagem Elétrica Vertical-SEV), imagens de sensoriamento remoto (SR) e mapeamento geológico local. Assim, foi possível compor uma modelagem geoelétrica de contaminação da área, a fim de indicar o quão afetado estão os corpos hídricos superficial e subterrâneo, além do solo, adjacente ao lixão. Além disso, foi possível estimar uma tendência de contaminação dos rios que cortam ou margeiam 
o município, e que deságuam na bacia hidrográfica do rio Branco, principal rio que corta o Estado (NE-SW).

\subsection{Localização e caracterização física da área de estudo}

O município possui área de $48.263 \mathrm{~km}^{2}$, situa-se na parte sul do estado de Roraima, na margem direita do curso médio do rio Branco (Figura 1). Limita-se a norte com os municípios de Iracema e Mucajaí, a sul com município de Rorainópolis e a oeste com o Distrito de Catrimani. O acesso por via terrestre é feito através da rodovia federal BR 174, sendo que a sede do município dista 600 km de Manaus e 135 km de Boa Vista, capitais dos estados do Amazonas e Roraima, respectivamente. Segundo o Instituto Brasileiro de Geografia e Estatística (IBGE), o município possuía 18.398 habitantes no último censo de 2010 e estimada para 2017 em 20.807 habitantes, dos quais mais de $60 \%$ concentrados na zona urbana.

Em 1998 a Companhia de Pesquisa de Recursos Mineriais (CPRM) elaborou um Programa de Integração Mineral em Municípios da Amazônica (PRIMAZ), versando sobre o Saneamento Básico da Cidade de Caracaraí, Estado de Roraima. Contudo, as NBR 8.419/1992 e NBR 13.896/1997 não foram seguidas, pois a alocação dos resíduos sólidos urbanos (RSU) do município é inadequada até o presente momento. Assim, o que impera é a disposícção dos RSU na forma de lixão à ceu aberto.

O lixão localiza-se em uma estrada vicinal perpendicular à rodovia BR 174/km 453 na porção oeste (Roraima-Amazonas) (Figuras 1 e 2A-D). Os RSU gerados são de origem doméstica, pública, comercial e hospitalar. Segundo CPRM (1998) o município de Caracaraí produzia $2.893 \mathrm{~kg}$ de lixo diariamente. No entanto, este montante está muito defasado e valor atual não é conhecido. 


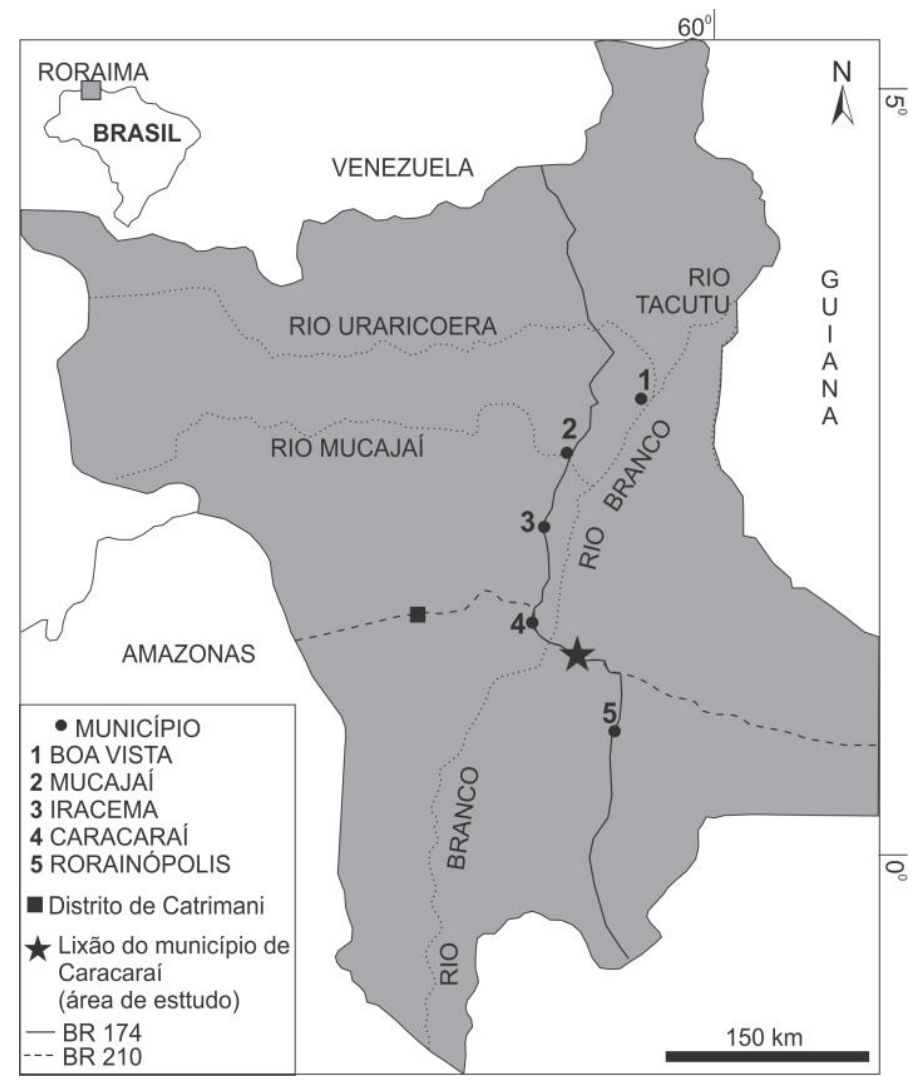

Figura 1. Mapa de localização.
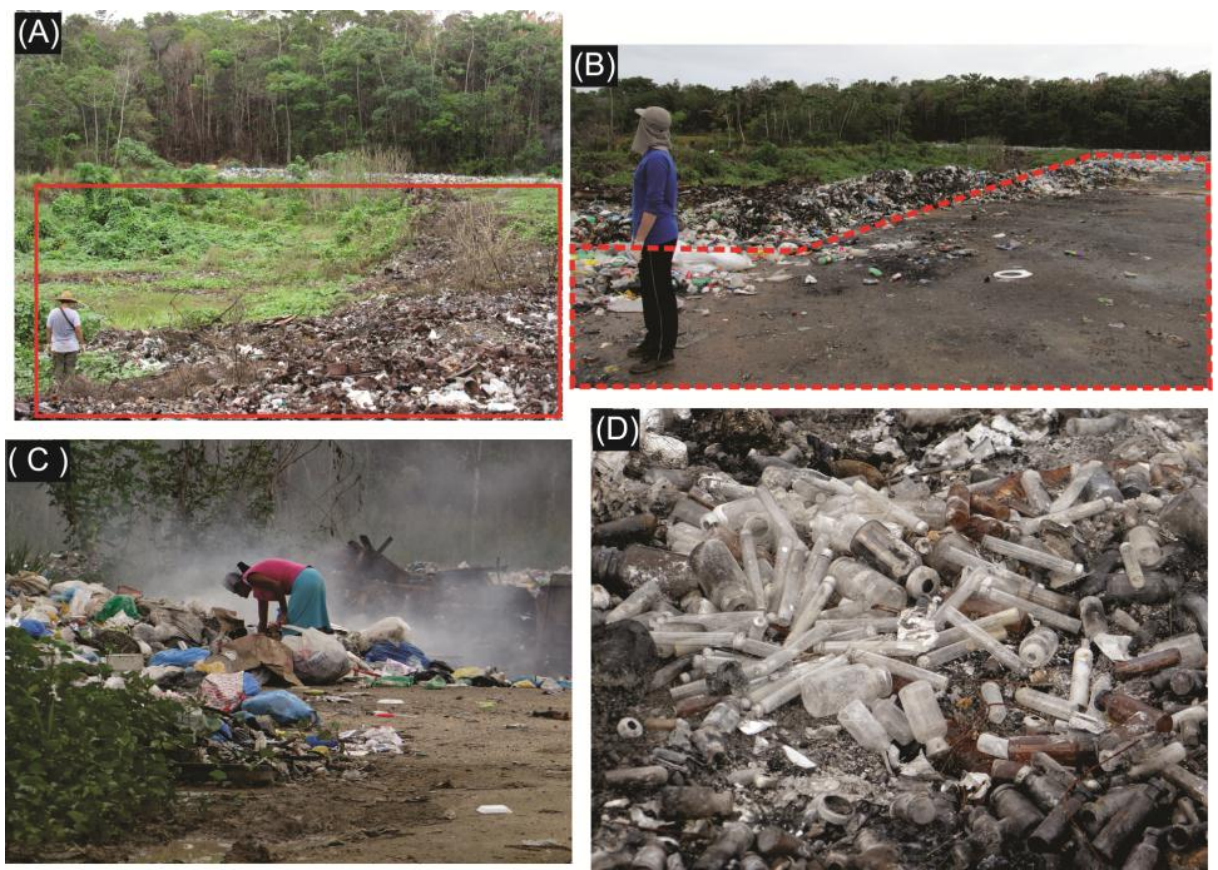

Figura 2. Aspectos físicos da área do lixão do município de Caracarai/RR. (A) Visão de dentro da cava do lixão (retângulo vermelho). (B) Área externa à cava indica o local onde o lixo é alocado antes de ir para cava (polígono vermelho pontilhado). (C) Catadores de lixo. (D) Material hospitalar incinerado. Fonte: Fotos cedidas por F.W.S Carvalho e G.R de Moraes, 2016. 


\subsection{Contexto hidrológico, geomorfológico e geológico simplificados}

O município de Caracaraí é drenado pela bacia hidrográfica do rio Branco, afluente pela margem esquerda do rio Negro, que por sua vez é distributário do rio Solimões. O rio Branco ao atravessar o município de Caracaraí, tem sentido geral NNE-SSW (CPRM, 1998) (Figura 3). Este é principal rio que corta o estado de Roraima, sendo bastante denso e formado pela união dos rios Uraricoera e Tacutu, com $45.530 \mathrm{~km}^{2}$.

De acordo com Franco et al. (1975), a porção setentrional do município tem com feição geomorfológica o Planalto Residual de Roraima. Este planalto é Constituído por rochas cristalinas de idades proterozóicas, abrangendo quase $40 \%$ da área municipal, onde predominam colinas com vales encaixados, algumas vezes associados a pontões ou cristas com altitudes de 400 a $940 \mathrm{~m}$. Feições morfoestruturais mantidas por serras e relevos colinosos, exibem cristas com vertentes de forte declividade, modeladas por drenagens juvenis. Para a porção sul, ocorre o Pediplano Rio Branco-Rio Negro, que ocupa cerca de $60 \%$ da área do município. Esta área apresenta baixas altitudes, declividade suave para sul e rede de drenagem mal definida. Além disso, esta unidade destaca-se, por sua expressão superficial, área de aplainamento conservada e de acumulação inundável de menor expressão, e as planícies fluviais inundáveis, marginais aos principais cursos d'água da região.

O caráter geológico mostra que a área do lixão está inserida sobre a unidade de Depósitos Aluvionares e de Terraços. Esta unidade compreende materiais arenosos e argilosos, sendo rodeada de noroeste a sudeste pela Formação Araí, e de norte a sudeste por unidades pertencentes ao embasamento como as ortoderivadas da Suíte Metamórfica Rio Urubu e os granitóides das suítes Mapuera e Mucajaí (CPRM, 2004) (Figura 4). O mapeamento geofísico em questão, visa configurar a possível tendência de contaminação dos corpos hídricos que cortam o município de Caracaraí, e que deságuam na bacia hidrográfica do rio Branco. O caráter essencialmente sedimentar da área, além do fácil acesso, contribuiram no bom desempenho da metodologia geofísica empregada. 


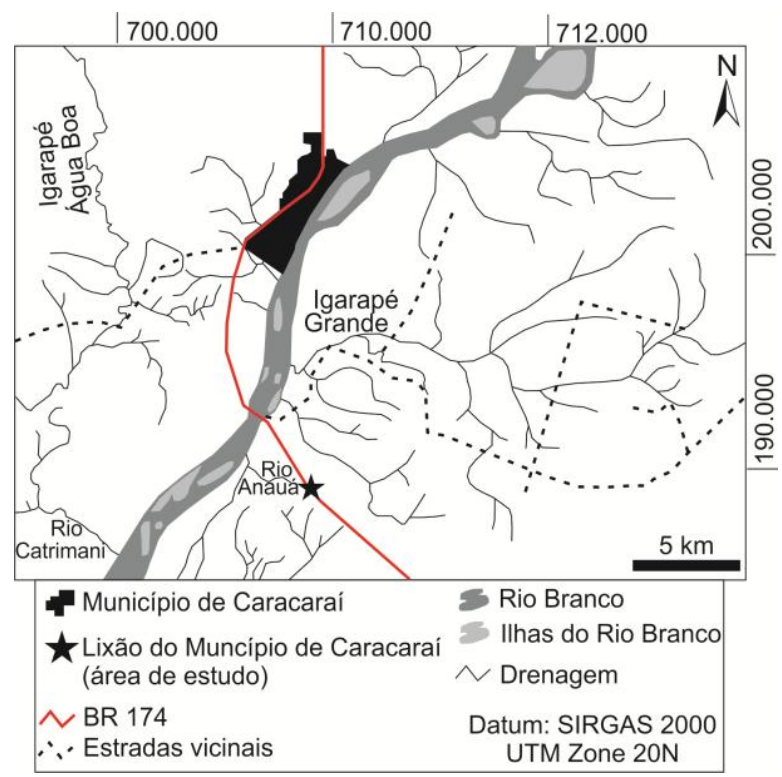

Figura 3. Mapa de drenagem da área.

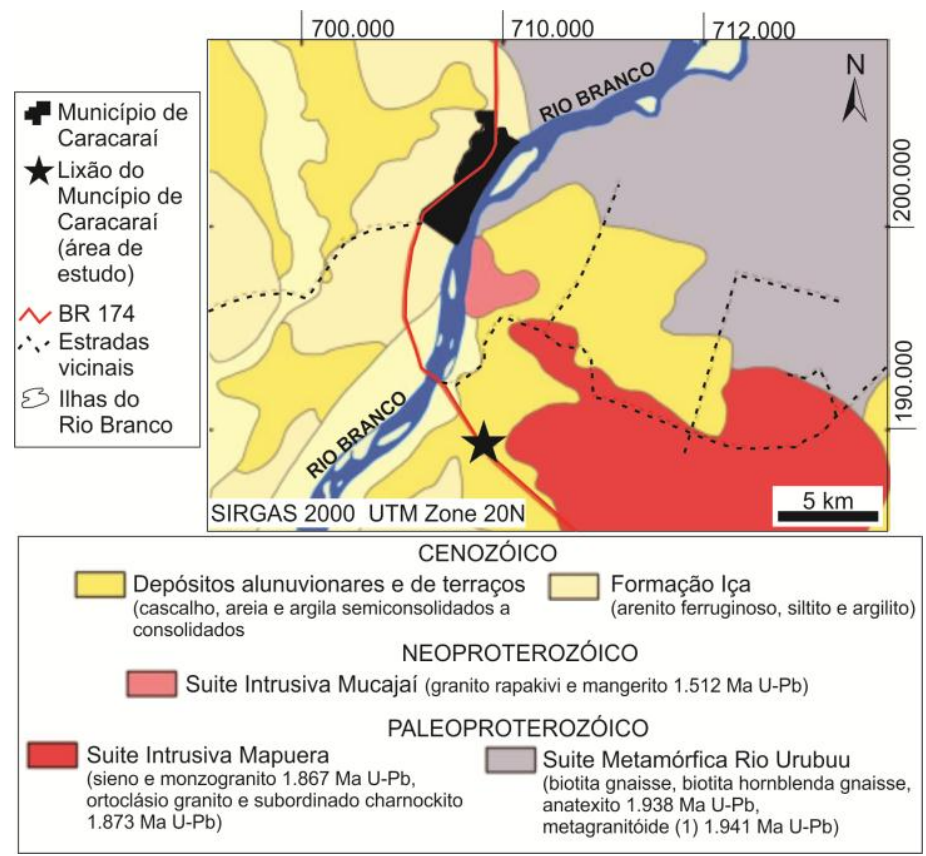

Figura 4. Mapa geológico da área. Fonte: modificado de CPRM (2004).

\section{METODOLOGIA}

Os produtos de sensoriamento remoto (SR) utilizados, consistiram nas imagens do satélite Landsat 8, disponíveis pelo Serviço Geológico Americano (earthexplorer.usgs.gov) referente a data de 24/01/2016, adquiridas já georreferenciadas e corrigidas relativo à cena 232/058 (órbita/ponto). Os produtos das imagens resultaram da composição de bandas red, green, blue "RGB" (R6G5B4) com resolução espacial de 30 m e da fusão das bandas R6G5B4 com a banda 8 (pancromática), 
resultando na resolução espacial de $15 \mathrm{~m}$. O processamento foi executado no Laboratório de Ensino de Geociências (LABENGEO)/Universidade Federal de Roraima com auxílio do software ArcGis.

Os ensaios elétricos foram realizados nos dias 23 e 24/04/2016, abrangendo a coleta de dez Sondagens Elétricas Verticais (SEV) com arranjo Schlumberger no lixão do município de Caracaraí (Figura 5). As sondagens foram executadas com o uso do resistivímetro cedido pelo Instituto de Geociências/Universidade Federal do Amazonas.

O levantamento foi executado de modo sistemático, cujo dispositivo de medida é composto de dois eletrodos metálicos de corrente (A e B), ambos conectados por cabos a uma fonte de corrente elétrica contínua ou alternada de baixa frequência disposta em série a um amperímetro, e por dois eletrodos de potencial ( $\mathrm{M}$ e $\mathrm{N}$ ) conectados em série a um voltímetro. Os quatros eletrodos são cravados na superfície do terreno (Figura 6A-B), em seguida mede-se a diferença de potencial $(\Delta \mathrm{V})$. Após a estabilização mede-se o valor de resistência ( $\mathrm{R}$, medida em $\Omega$ ) para o cálculo da resistividade aparente $\left(\rho_{\mathrm{a}}\right)$ utilizando a equação:

$$
\rho=\mathrm{k} . \Delta \mathrm{V} / \mathrm{I}
$$

Onde: $\mathrm{k}$ (coeficiente geométrico dependente do arranjo dos eletrodos na superfície), $\Delta \mathrm{V}$ (diferença de potencial elétrico entre os eletrodos de potencial, mili Volt), e I (corrente contínua aplicada entre os eletrodos de corrente, medida em Amper).

Ao término deste cálculo os valores de $\rho_{\mathrm{a}}$ são plotados em uma ficha de campo, configurando assim, o esboço da curva (em escala bi-log) para avaliação prévia do comportando do terreno (camadas resistivas e/ou condutivas). Posteriormente, os dados foram processados com auxílio dos programas IPIWin2 (permite mensurar as espessuras das camadas rochosas em profundidade) e Surfer (modelar em 3D o comportamento do fluido contaminador). 


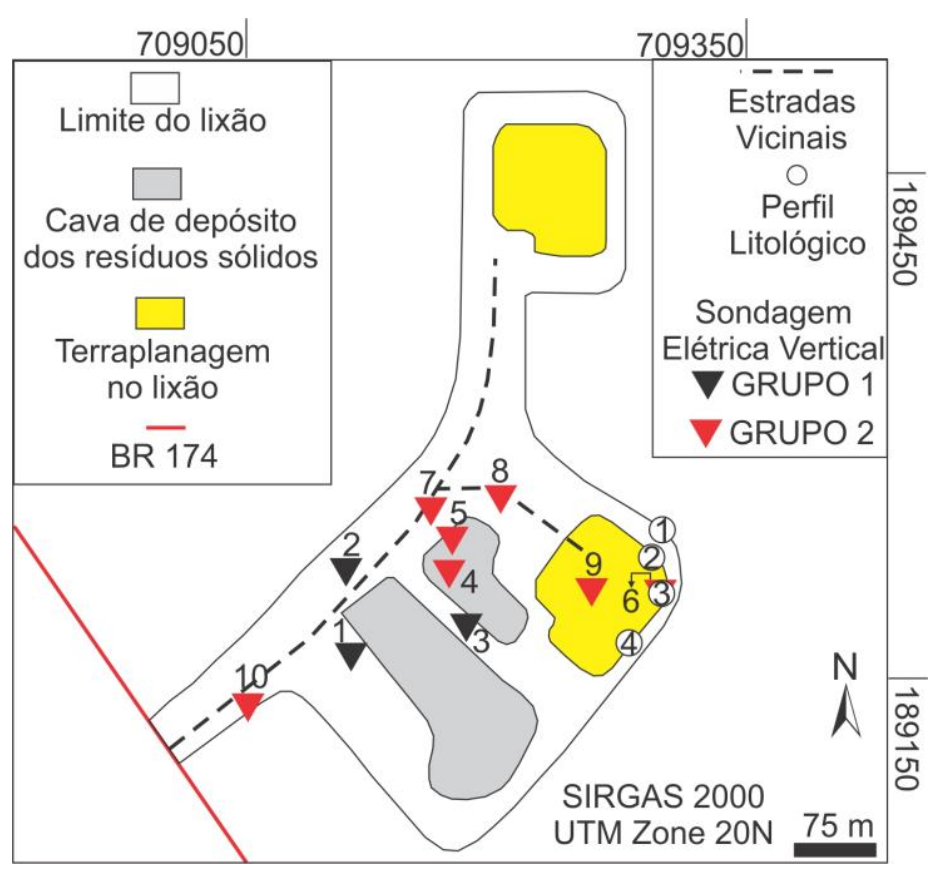

Figura 5. Mapa de pontos de SEV e dos perfis litológicos no lixão.
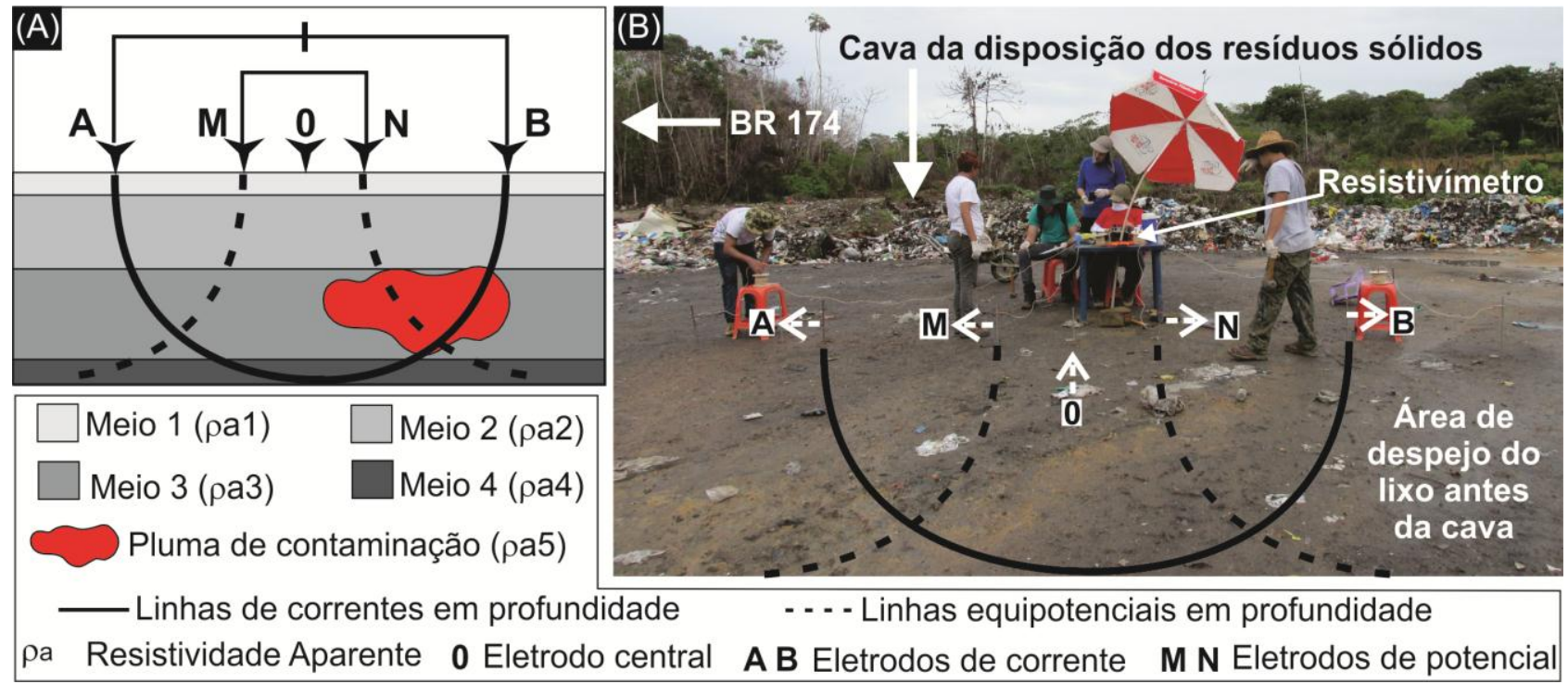

pa Resistividade Aparente $\mathbf{0}$ Eletrodo central A B Eletrodos de corrente M N Eletrodos de potencial

Figura 6. Exemplificação da coleta de dados geofísicos. (A) Desenho esquemático de uma pluma de contaminação. (B) Sondagem Elétrica Vertical com dispositivo de leitura Schlumberger. Fonte: Fotos cedidas por F.W.S Carvalho, 2016.

\section{RESULTADOS E DISCUSSÕES}

\subsection{Apresentação dos dados}

O mapeamento geológico local dos afloramentos expostos na área do lixão, revelaram litotipos siltosos e arenosos, ora laterizados ora não. Essas características não foram descritas para 
os Depósitos Aluvionares e nem para a Formação Araí, que é a segunda unidade sedimentar mais próxima da área, sendo observado horizonte silto-arenoso mosqueado com esparsas concreções lateríticas, crosta laterítica colunar, crosta laterítica desmantelada, linha de pedra e horizonte arenoso (Figuras 7A-C e 8).

As crostas lateríticas colunares tem coloração vermelho-alaranjada, porosa e mineralogia de oxi-hidróxidos de Fe e Al, quartzo leitoso, hematita e goethita. É importante ressaltar que a goethita não apresenta estrutura laminar, indício de que não é marcante a variação do nível do lençol freático na região. As concreções desmanteladas são formadas por fragmentos angulosos a subangulosos sustentados por matriz silto-arenosa e mineralogia análoga a da crosta laterítica colunar. É considerada como desmantelada, devido à alta angulosidade (pouco transporte) e composição que remete a crosta. A linha de pedra é formada por seixos e blocos de quartzo metamórfico e subordinados fragmentos da crosta (Figuras 7A-C e 8).
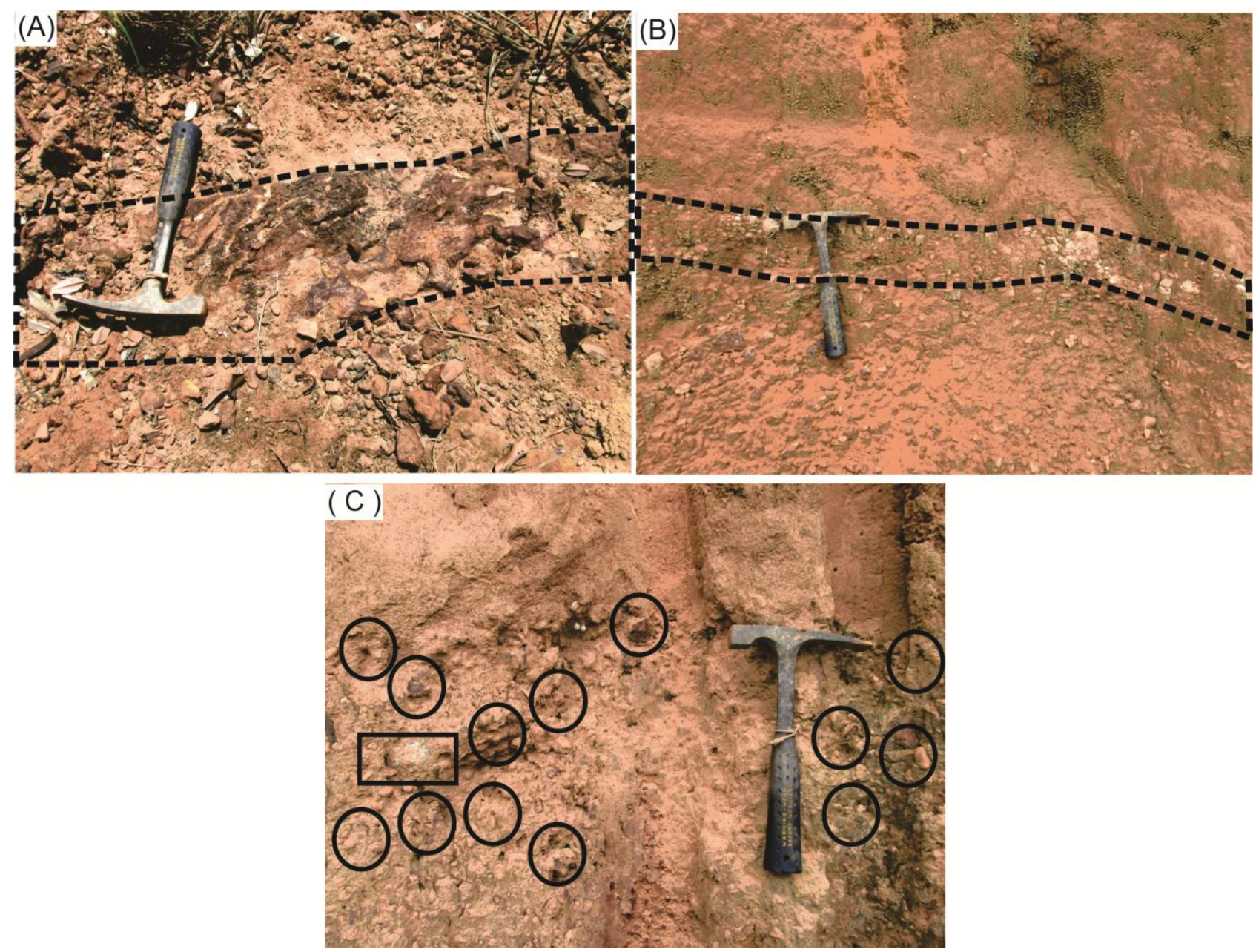

Figura 7. Aspectos geológicos de campo dos horizontes individualizados para a área. (A). Crosta laterítica (polígono preto pontilhado). (B) Linha de pedra de quartos leitosos em parte metamorfizados (polígono preto). (C) Concreções lateríticas desmanteladas em horizonte arenoso (círculos pretos referentes as 
concreções e retângulo preto um quartzo leitoso metamorfizado). Fonte: Fotos cedidas por F.W.S Carvalho, 2016.

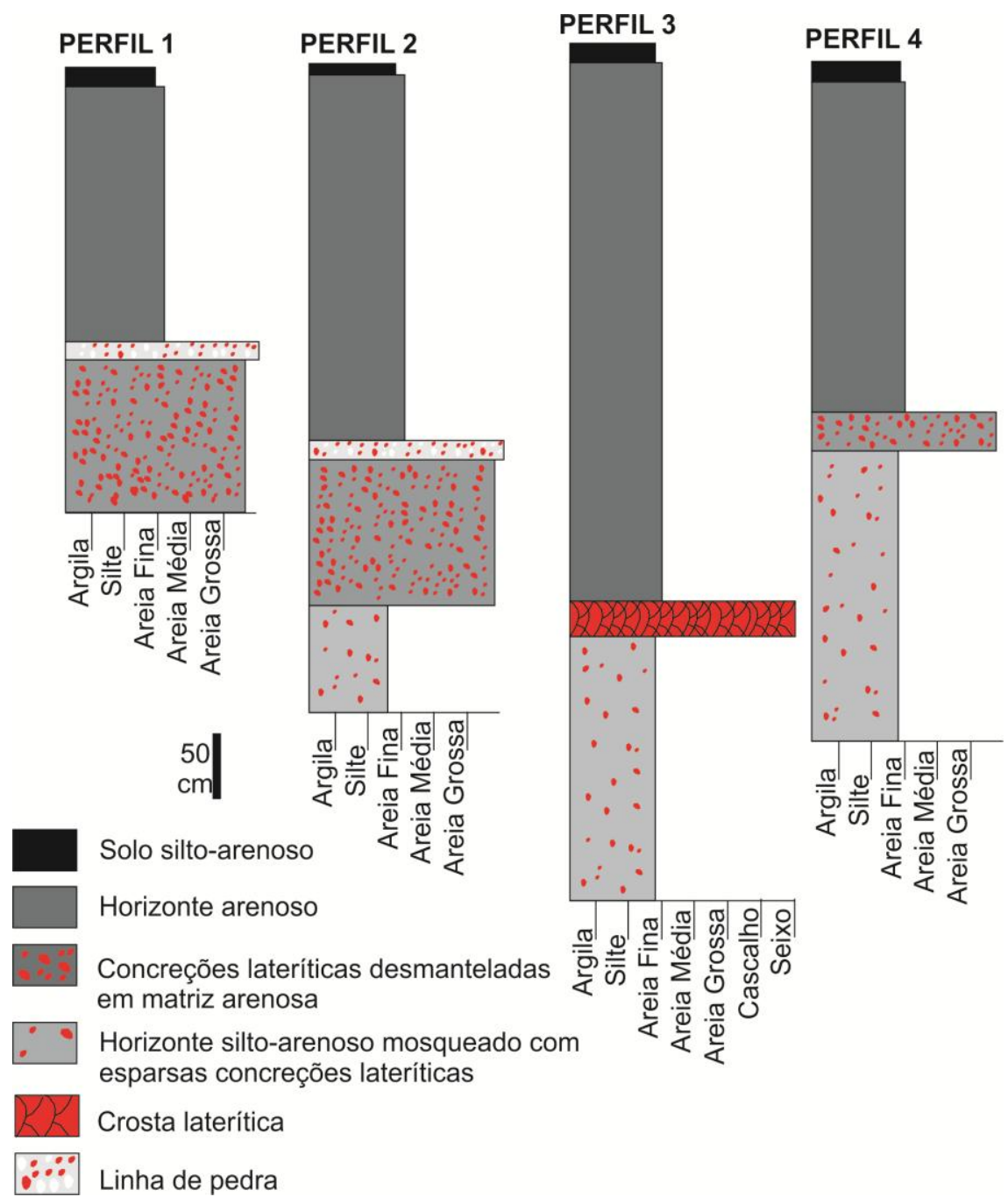

Figura 8. Perfis litológicos adjacentes ao local de lançamento dos resíduos sólidos.

A análise das curvas de $\rho_{\mathrm{a}}$ geradas permitiu individualizá-las em dois grupos geoelétricos, de acordo com os aspectos semelhantes entre si, por exemplo, o local de realização dos ensaios, a faixa de variação da resistividade e o comportamento geométrico da curva.

\subsubsection{Grupo geoelétrico 1}

Compreende três ensaios (SEV's 1-3) (Figuras 5 e 9) com AB/2 de 24 m, realizados paralelamente e a distância de 8 a $15 \mathrm{~m}$ da principal cava de resíduos sólidos do aterro. Os terrenos superficiais mapeados são areno-argilosos com concreções lateríticas roladas.

As curvas do grupo apresentaram geometria convexa e côncava, com três convexidades e duas concavidades (Figura 9). As SEV's 1 e 2 foram efetuadas com proximidade de $50 \mathrm{~m}$ uma da 
outra e distância de 10 e 15 m da cava de resíduos do aterro, respectivamente. As curvas são caracterizadas pelas quantidades de picos e quedas bruscas nas mesmas profundidades de leitura, atingindo picos de até $9.936 \Omega$.m e quedas para valores de até $176 \Omega$.m. A primeira convexidade

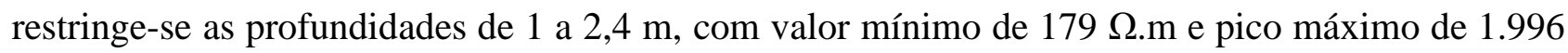
$\Omega . \mathrm{m}$ em $1,8 \mathrm{~m}$. A segunda convexidade limita-se as profundidades de 2,4 a 5,5 m, com valores variando de $179<\rho_{\mathrm{a}}<9.936 \Omega \mathrm{m}$, e pico em 4,2 m. A terceira convexidade ocorre entre as profundidades de 5,5 a $24 \mathrm{~m}$, entretanto, apresentam distinções quanto ao comportamento da curva, na SEV 1 a convexidade é bem acentuada com valores na faixa de $345<\rho_{\mathrm{a}}<7.642 \Omega$.m, enquanto que na SEV 2 é bem suave com valores na faixa de $721<\rho_{\mathrm{a}}<945 \Omega . m$ (Figura 9).

A SEV 3 foi realizada com proximidade de cerca de $75 \mathrm{~m}$ em relação as SEV's 1 e 2, e distância de $8 \mathrm{~m}$ da cava de resíduos sólidos (Figuras 5 e 9). Contudo, diferencia-se por localizar-se em um barranco protegido dos resíduos sólidos e pela sua curva ser bem mais suave. Suas três convexidades restringem-se as respectivas profundidades e valores: (1 $1^{\mathrm{a}}$.) 1 a 1,8 $\mathrm{m}$ com valores de $825<\rho_{\mathrm{a}}<1.329 \Omega . \mathrm{m} ;\left(2^{\mathrm{a}}\right.$.) 1,8 a $3,2 \mathrm{~m}$ com valores de $576<\rho_{\mathrm{a}}<3.080 \Omega$.m; e (3 $3^{\mathrm{a}}$ ) 3,2 a $24 \mathrm{~m}$

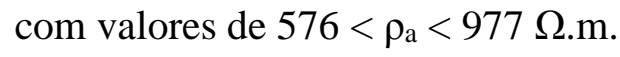
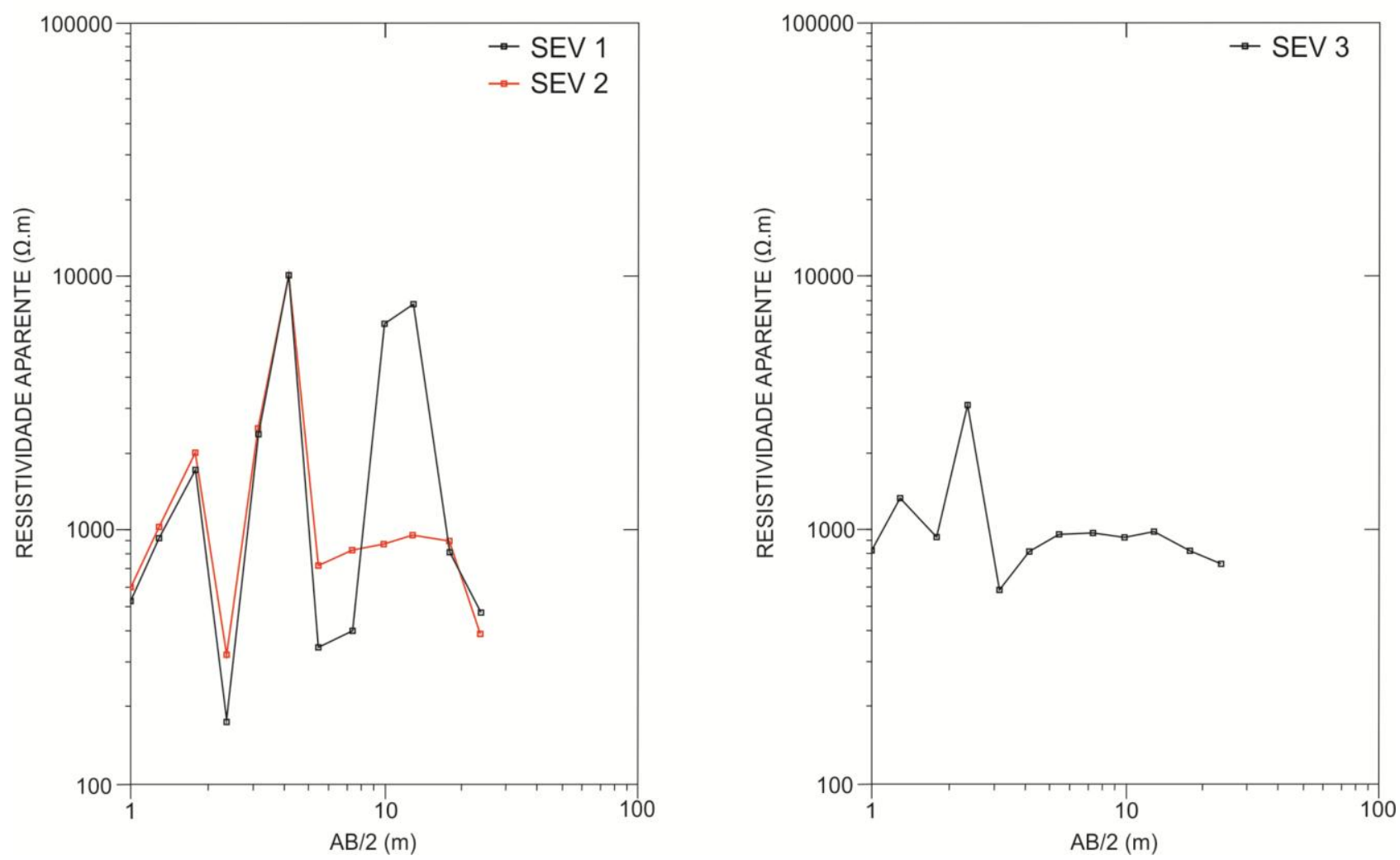

Figura 9. Curvas de resistividade elétrica do grupo geoelétrico 1. 


\subsubsection{Grupo geoelétrico 2}

Engloba sete levantamentos (SEV's 4-10) efetuados nas proções norte, NE, leste, SW e central do lixão (Figura 5). Os terrenos superficiais mapeados variaram de arenosos a siltoarenosos, com subordinadas concreções lateríticas. As curvas do grupo 2 apresentaram quatros geometrias distintas (Figura 10):

a) Convexa (SEV's 4, 5, 8 e 9): na $\mathrm{SEV} 4$ a primeira convexidade é bem acentuada, restringindo-se as profundidades de 1,3 a $7,5 \mathrm{~m}$, com valor mínimo de $6.433 \Omega$.m e pico máximo de $25.502 \Omega$.m em 4,2 m de profundidade. A segunda convexidade é bem diminuta e suave, com profundidades de 7,5 a 13 m, e valor mínimo de $1.906 \Omega$.m e máximo de 2.690 $\Omega . \mathrm{m}$. As convexidades da SEV 5 restringem-se as profundidades de 1 a 4,2 m e 4,2 a $18 \mathrm{~m}$,

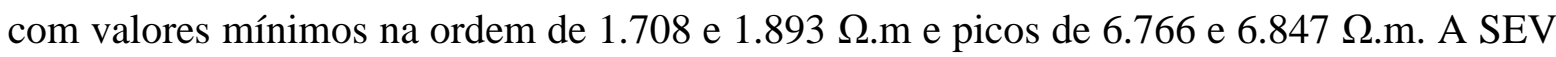
8 é formada por uma grande convexidade que se limita as profundidades de 1,3 a $24 \mathrm{~m}$, e

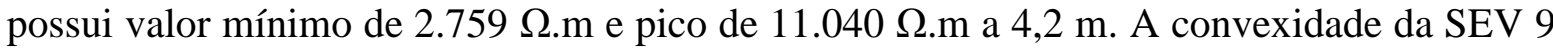
abrange as profundidades de $1 \mathrm{a} 24 \mathrm{~m}$, com valor mínimo de $3.522 \Omega$.m e pico de 12.150 $\Omega . \mathrm{m} \mathrm{em} 3,2 \mathrm{~m}$.

b) Convexa e semi-retilinea (SEV 6): a convexidade desta sondagem limita-se as profundidades de 1 a 4,2 m, com valor mínimo de $1.703 \Omega$.m a 1 m e pico máximo de 8.953 a 3,2 m. De 4,2 a $13 \mathrm{~m}$ a curva é semi-retilínea com valores na faixa de 4.526 a $3.032 \Omega . m$.

c) Convexa e côncava (SEV 7): a sondagem apresenta quatro convexidades e três

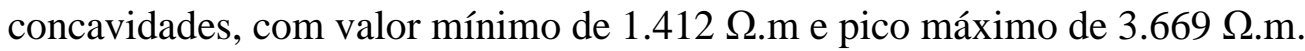

d) Ascendente e convexa (SEV 10): esta sondagem ascende de $1 \mathrm{~m}$ de profundidade com valor de $942 \Omega . m$ e até $5,5 \mathrm{~m}$ com valor de $15.176 \Omega . \mathrm{m}$, formando uma convexidade no declínio de $10.590 \Omega . \mathrm{m}$ em 7,5 $\mathrm{m}$ de profundidade. A segunda convexidade ocorre entre 7,5 e $18 \mathrm{~m}$,

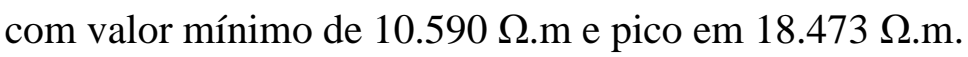



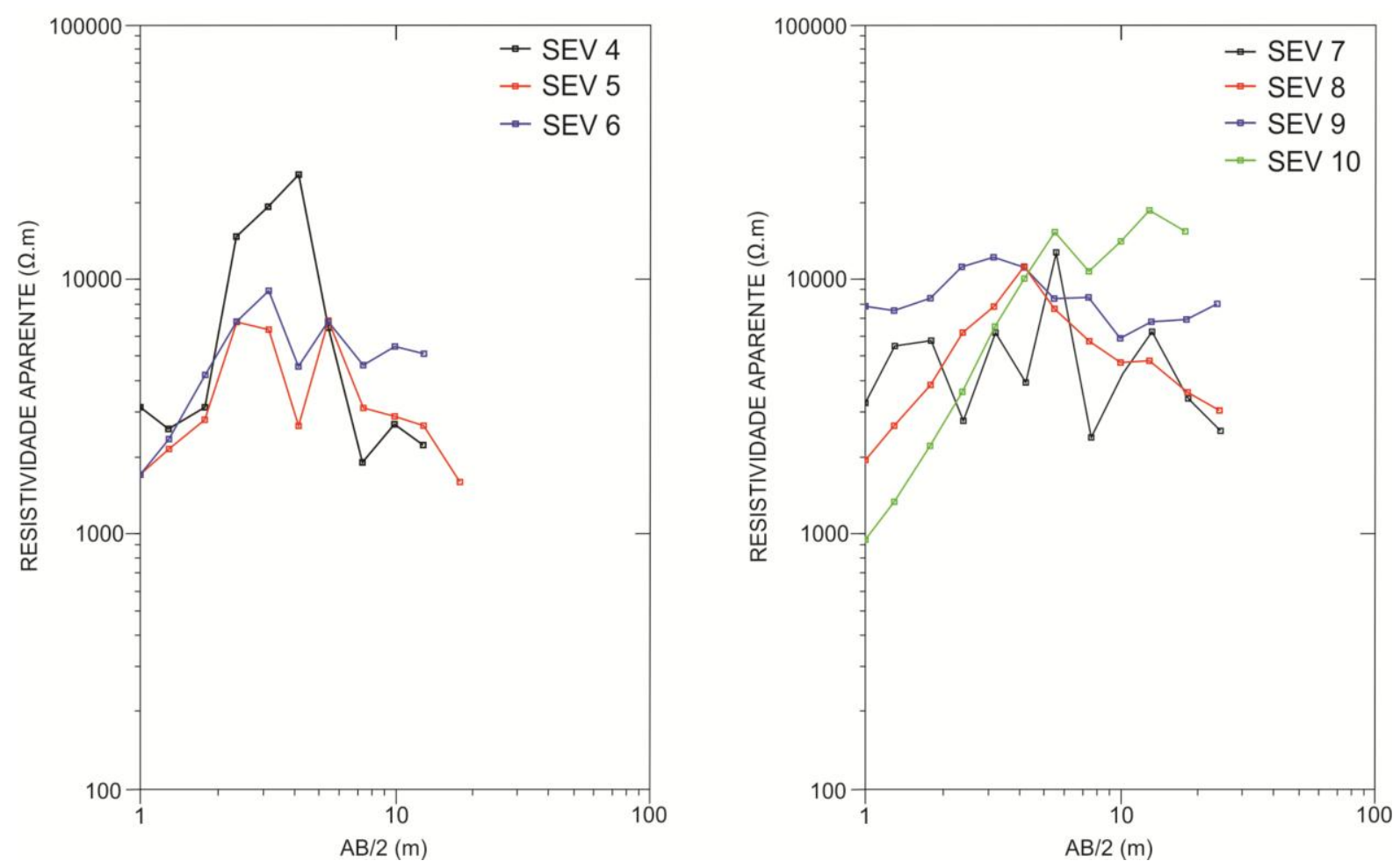

Figura 10. Curvas de resistividade elétrica do grupo geoelétrico 2

\subsection{Integração dos dados}

Segundo a CPRM (2004) o mapeamento geológico sistemático realizado na área de estudo é referente aos Depósitos Aluvionares e de Terraços, composto predominantemente por cascalho, areia e argila semi consolidados a inconsolidados. E, devido ao fato de anteriormente não terem sido descritos crostas lateríticas para os Depósitos Aluvionares e Terraços e a presença marcante de quartzo metamórfico em quase todas as camadas estudadas, sugere-se que tais depósitos lateríticos sejam oriundos da Suíte Metamórfica Rio Urubu, único embasamento metamórfico da região, e que dista cerca de 10 a 14 km do lixão.

Na literatura geofísica Paranis e Orellana (1970), Paranis (1971), Orellana (1972), Keller e Frischknecht (1977), Telford et al. (1990), Kearey et al. (2009), Souza (2010), Braga (2016) entre outros, é usualmente aceito que os valores de resistividade variam de acordo com a predominância do material geológico em subsuperfície. Assim, as altas resistividades são atribuídas as camadas arenosas, enquanto, que as baixas resistivas são atribuídas as camadas argilosas. Ensaios geofísicos realizados por Laureano (2007) em camadas lateríticas no estado do Mato Grosso e por Souza (2010) em paleossolos lateríticos na região nordeste do estado do Pará, indicaram valores de resistividades mais elevados para as lateritas em relação a camadas sedimentares mais arenosas. Os atributos exibidos pelos referenciais bibliográficos foram utilizados para área, visto ao seu contexto 
geológico. Os valores de resistividades tornam-se diferentes destes quando se mapeia áreas contaminadas, pois a resposta elétrica do material geológico tende a diminuir bruscamente, com valores de resistividades até dez vezes menores que o normal (Braga, 2007).

Os ensaios do grupo geoelétrico 1 (Figura 9) efetuados a distância de 8 a 15 m da cava de despejo dos resíduos apresentaram as menores resistividades para a área de estudo. Valores estes condizentes com indícios de contaminantes. Nas SEV's 1 e 2 observa-se que os menores valores se

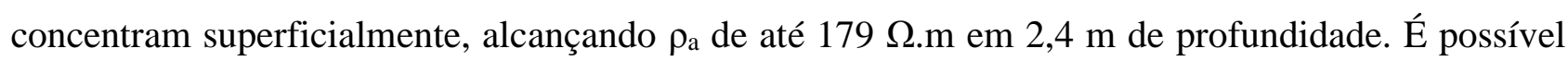
também identificar resquícios nas profundidades de 5,5; 7,5 e $24 \mathrm{~m}$, com presença de valores que atingem até 345 S.m. Embora a SEV 3 esteja localizada em uma região protegida dos resíduos é possível distinguir discretos traços de uma possível contaminação as profundidades de 1,8; 3,2 e 4,2, com valores de até $576 \Omega . m$.

Os valores obtidos para o grupo geoelétrico $1\left(175<\rho_{\mathrm{a}}<580 \Omega\right.$.m) não podem ser assoaciados a valores naturais de meio geológico para área (camadas arenosas ou siltosas ou laterizadas), sendo relacionados a contaminação decorrente do processo de lixiaviamento do chorume. Segundo, Gallas et al. (2005) as porções contaminadas em subsuperfície, são os locais que paresentam as menores resistividades em aterros sanitários, uma vez que, aumentam consideravelmente o conteúdo iônico da área facilitando a propagação de corrente elétrica. Estudos realizados, por Braga (2007), Elis e Zuquette (2002) e Souza e Paz (2018) comprovam que os valores de resistividade em ambientes contaminados por chorume, podem diminuir em até dez vezes o valor natural da área, possibilitando traçar mapas de resistividade da zona não saturada (resistividade natural do meio geológico) e os pontos de saturação por contaminantes (pluma de contaminação com resistividade baixa).

As resistividades elétricas do grupo geoelétrico 2 (Figura 10) apresentaram valores de 942 a

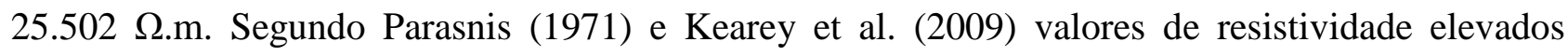
podem ser atribuídos a materiais arenosos e valores de resistividade baixos geralmente são atribuídos a materiais argilosos. Entretanto, a presença de concreções lateríticas porosas podem acarretar aos valores de $\rho_{\mathrm{a}}$ aumentos acentuados em relação as camadas arenosas (Souza e Carvalho, 2017; Souza et al. 2013; Souza, 2010; Laureano, 2007).

No ensaio da SEV 6 realizado sobre o perfil litólogico 3, a $\rho_{a}$ varia conforme a litologia (Figura 11). A leitura de $1 \mathrm{~m}$ tem-se o solo silto-arenoso e o horizonte arenoso com resistividade aparente de $1.703 \Omega . \mathrm{m}$, denotando o valor mais baixo da curva, consequência principalmente da influência do solo mais argiloso. A partir de 1,3 a 4,2 m de profundidade, a $\rho_{\text {a corresponde ao }}$ horizonte arenoso com valores na faixa de $2.351<\rho_{\mathrm{a}}<8.953 \Omega$.m. O declínio da curva em 4,2 m, provavelmente, deve-se ao maior empacotamento da camada arenosa. Aos de 5,5 m de 
profundidade é observado crosta laterítica e o horizonte silto-arenoso mosqueado com concreções

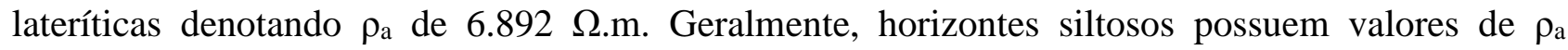
inferiores a horizontes arenosos, no entanto, a presença da crosta laterítica deve ser o principal fator que acarretou em uma resistividade semelhante ao horizonte arenoso. De 7,5 a $13 \mathrm{~m}$ de profundidade não foi possível agregar valores devido ao perfil possuir apenas $6,5 \mathrm{~m}$ de comprimento. Entretanto, em campo contatou-se que a superfície era composta pelo mesmo material do horizonte, e pela retilinearidade da curva e valores na faixa de 4.584 a $5.428 \Omega . \mathrm{m}$, possivelmente trata-se da continuidade do horizonte silto-arenoso mosqueado.

Nas SEV's 4 e 10 é possível identificar possíveis crostas lateríticas nos picos que atingem de 14.995 a 25.505 S.m. Nas SEV's 5, 6 e 10 constata-se a influência dos solos superficiais mais argilosos e silto-arenosos, denotando valores de 942 a $1.708 \Omega . \mathrm{m}$, sempre a $1 \mathrm{~m}$ de profundidade. O horizonte arenoso é reconhecido em todas as sondagens exibindo valores de 2.000 a $10.000 \Omega$.m, e de 10.000 a $14.000 \Omega$.m, possivelmente quando ocorre com concreções lateríticas.
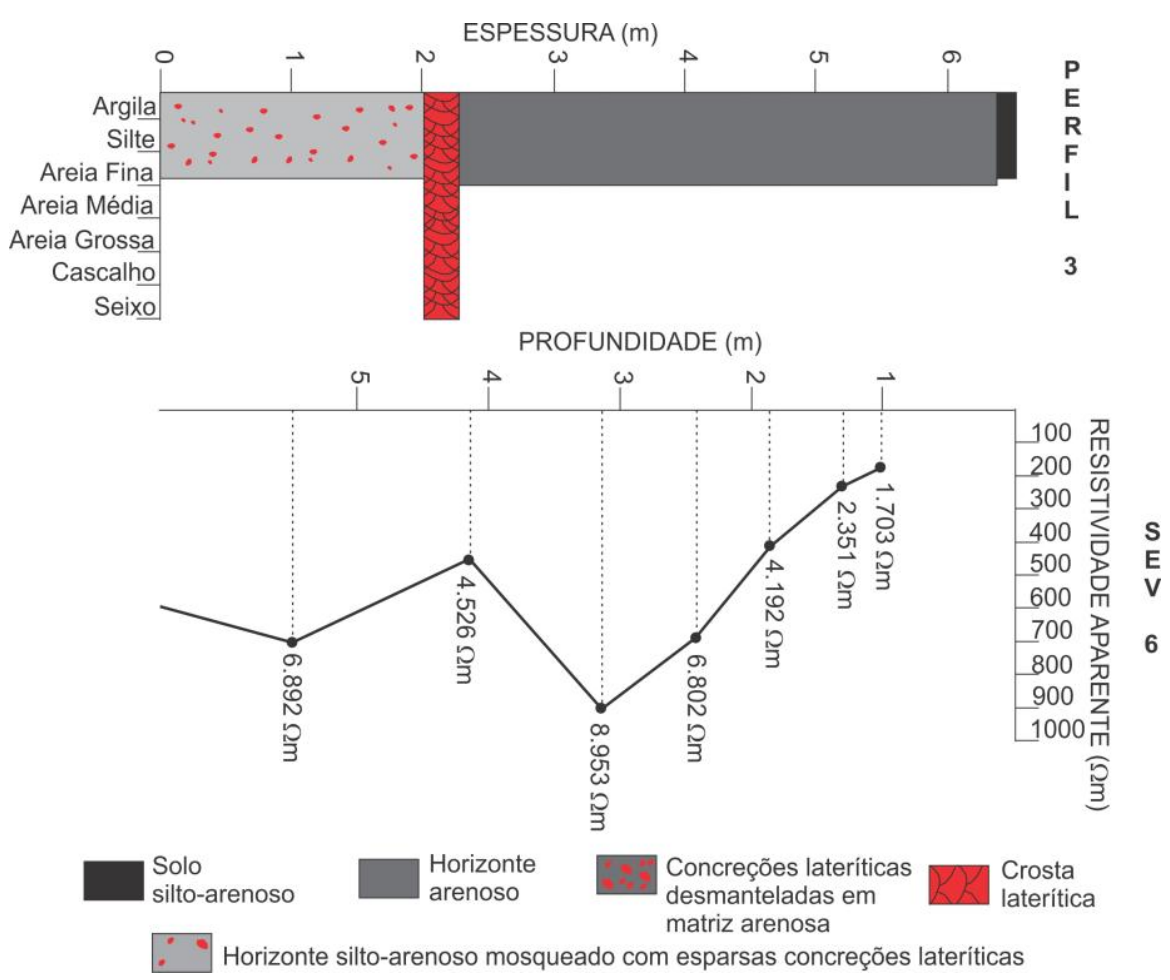

Figura 11. Comparativo entre o dado geológico (perfil litológico) e o dado geofísico (sondagem elétrica vertical).

\subsubsection{Modelo hipotético de contaminação}

O mosaico de isovalores demonstrou a distribuição lateral de resistividade em oito níveis de investigações, apontando onde estão as zonas resistiva $\left(900<\rho_{\mathrm{a}}<25.000 \Omega . \mathrm{m}\right)$ e as condutivas 
$\left(179<\rho_{\mathrm{a}}<576 \Omega\right.$.m) na área do lixão de Caracaraí. É constatado, que as porções anômalas condutivas ocorrem sob os depósitos de resíduos sólidos de 1 a 2,4 $\mathrm{m}$ de profundidade, com dispersão suave aos 4,2 m em diante. Entre os níveis de 7,5 e $24 \mathrm{~m}$ é verificado faixas condutivas, sugerindo que tais contaminantes tendem a se acumular em subsuperfície, quando encontram materiais mais argilosos que permitam a sua acumulação (Figura 12).

$\mathrm{Na}$ área de estudo é pertinente que os contaminantes se concentrem pontualmente nas regiões adjacentes a cava de resíduos, com concentração superficial e migração vertical em profundidade. É possível inferir que a concentração superficial se deve ao lençol freático ser raso na área, identificado a partir da análise visual de um poço com água aflorando a $2 \mathrm{~m}$. Em períodos chuvosos o lençol raso funciona como meio de transporte para o chorume, facilitando a concentração, percolação e dispersão superficial dos contaminantes.

Não é identificável na área a atuação de planícies de inundação e nem vestígios do espraiamento e migração dos contaminantes. Este fato deve-se por conta do lixão estar localizado em um alto estrutural com cota altimétrica em torno de $70 \mathrm{~m}$ e baixíssima presença de drenagens, as quais encontram-se a mais de $1 \mathrm{~km}$ de distância do lixão. Este fator apoia que a concentração tende a ser preferencialmente gravitacional com percolação vertical de contaminantes, no qual o tempo de residência torna-se o principal fator de influência que permite o transporte dos contaminantes.

Os valores remetidos aqui são tratados como resquícios. Uma vez que comparados a estudos realizados no aterro sanitário de Boa Vista/RR (valores de até 36 S.m) (Andrade e Souza, 2015;

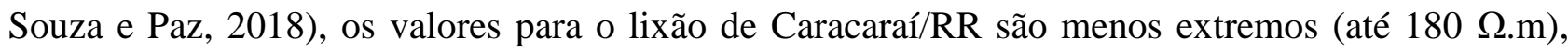
talvez por conta de este ser relativamente mais jovem e não sofrer influência acerca de planícies de inundação. Deste modo, o levantamento geofísico possibilitou identificar possíveis resquícios de contaminantes na porção central do lixão, que corresponde as adjacências da cava de resíduos sólidos, com valores na faixa de $179<\rho_{\mathrm{a}}<576 \Omega$.m. 


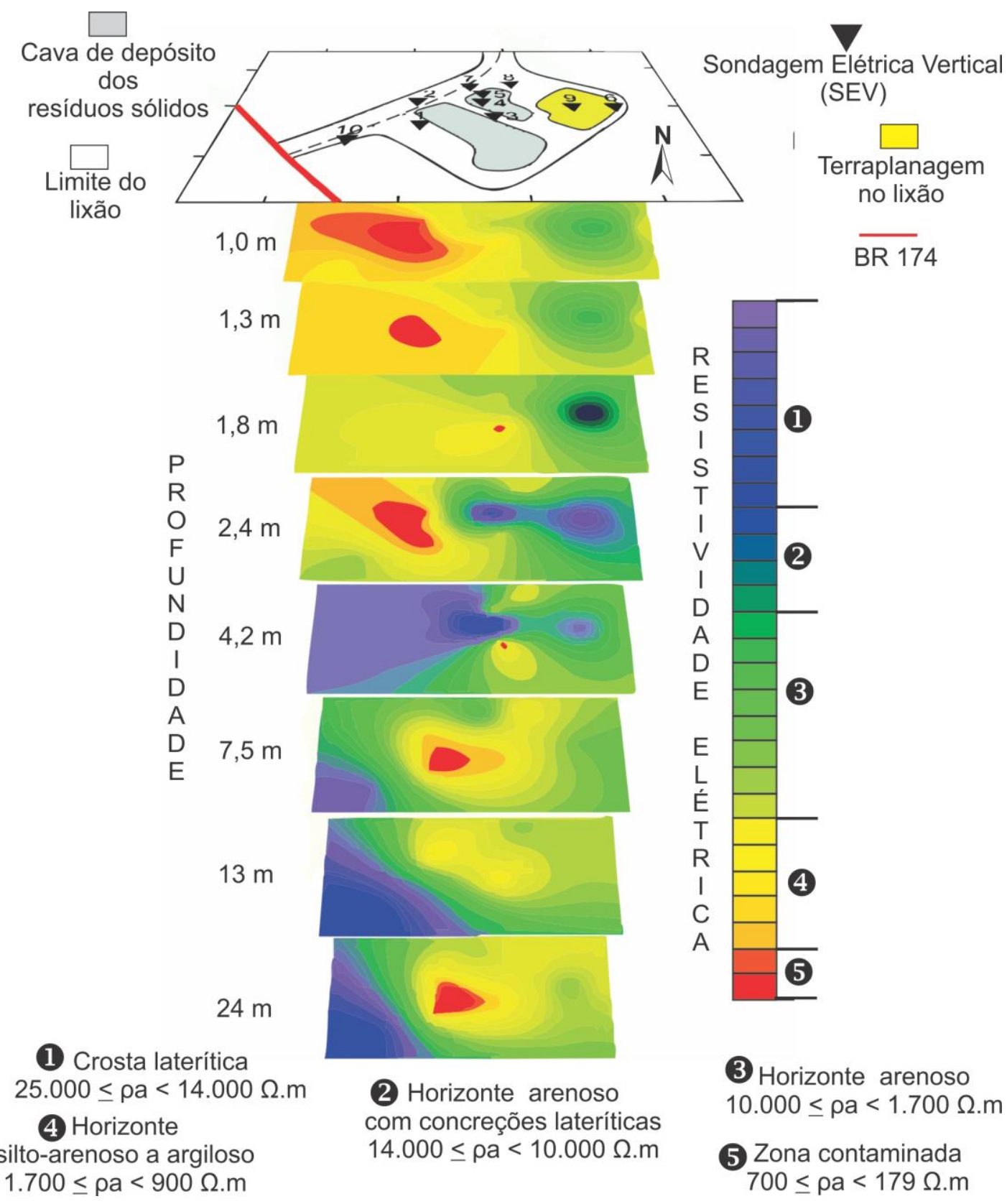

Figura 12. Modelo hipotético da contaminação do lixão do município de Caracaraí/RR.

\section{CONCLUSÕE E CONSIDERAÇÕES FINAIS}

As dez sondagens elétricas verticais executadas no lixão do município de Caracaraí, abrangendo leituras com até $24 \mathrm{~m}$ de profundidade conferiram dois comportamentos elétricos para a área. Para o grupo geoelétrico 2 (faixas norte, NE, leste, SW e central do lixão) distingui-se cinco zonas de resistividade: crosta laterítica $\left(14.000<\rho_{\mathrm{a}}<25.000 \Omega . \mathrm{m}\right)$, horizonte arenoso com crosta laterítica $\left(14.000<\rho_{\mathrm{a}}<10.000 \Omega . \mathrm{m}\right)$, horizonte arenoso $\left(2.000<\rho_{\mathrm{a}}<10.000 \Omega . \mathrm{m}\right)$, horizonte siltoarenoso com crosta laterítica $\left(6.500<\rho_{\mathrm{a}}<7.000 \Omega\right.$.m) e solo silto-arenoso a argiloso $\left(900<\rho_{\mathrm{a}}<\right.$ 


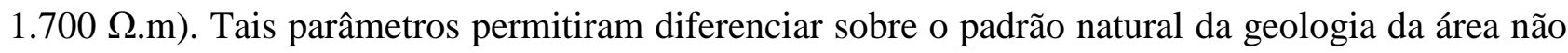
contaminada e o que seria um padrão anômalo correspondente a possíveis zonas contaminadas.

A zona contaminada (grupo geoelétrico 1) é caracterizada a partir do grupo geoelétrico 2, locada na porção central do lixão e a distância de 8 a $15 \mathrm{~m}$ da cava de resíduos sólidos. O grupo apresenta faixas condutivas com valores de $179<\rho_{\mathrm{a}}<589 \Omega$.m, que são caracterizadas como indícios de contaminantes. A contaminação é pontual e se concentra primordialmente nas adjacências e sobre a cava de resíduos.

As profundidades superficiais a contaminação é mais concentrada em função do nível do lençol freático ser raso ( $2 \mathrm{~m}$ de profundidade) que permite sua maior concentração e migração nas

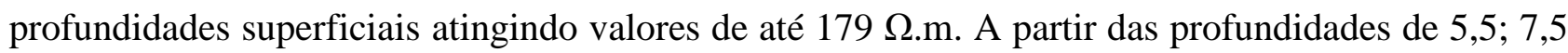
e $24 \mathrm{~m}$ foram localizados alguns pontos com resquícios de contaminantes com valores de resistividades entre $322<\rho_{\mathrm{a}}<589 \Omega$.m.

A migração dos contaminantes tendem a ser pontuais e verticais, pois o lixão está posicionado num alto estrutural e não há vestígios de planícies de inundação. Assim, a pluma não se espraia lateralmente e tende a migrar pontualmente e verticalmente segundo um gradiente gravitacional. Logo, a área mapeada eletricamente está contaminada apenas superficialmente, contudo, o fluido contaminador pode espraiar-se lentamente, caso não seja tomada nenhuma providência pelo poder público, isto é, adequar-se as normas brasileiras de construção e monitoramento de um aterro sanitário. E, infelizmente, isto até o presente momento não está sendo feito pelo Estado de Roraima, e consequentemente por nenhuma prefeitura.

\section{REFERÊNCIAS}

ANDRADE, G. A.; SOUZA, L. S. B. Caracterização geoelétrica do aterro sanitário de Boa Vista/RR. In: Encontro do Programa de Iniciação Científica, Boa Vista. Anais do XIV EPIC, 2015.

ASSOCIAÇÃO BRASILEIRA DE NORMAS TÉCNICAS (ABNT). NBR 10.004: informação e documentação: resumo: apresentação. Rio de Janeiro, 2004. 1 p.

ASSOCIAÇÃO BRASILEIRA DE NORMAS TÉCNICAS (ABNT). NBR 13.896: Aterros de resíduos não perigosos: critérios para projeto, implantação e operação. Rio de Janeiro, 1997. $12 \mathrm{p}$.

ASSOCIAÇÃO BRASILEIRA DE NORMAS TÉCNICAS (ABNT). NBR 8.419: Apresentação de projetos de aterros sanitários de resíduos sólidos urbanos. 1992. 7 p. 
BORTOLIN, J. R. M.; MALAGUTTI FILHO, W.M. Monitoramento temporal da pluma de contaminação no aterro de resíduos urbanos de Rio Claro (SP) por meio do método geofísico da eletrorresistividade. Geologia USP. Série Científica, 2012, São Paulo, 12 (3): 99-113.

BORTOLIN, J. R. M.; MALAGUTTI FILHO, W. M. Método da eletrorresistividade aplicado no monitoramento temporal da pluma de contaminação em áreas de disposição de resíduos sólidos urbanos. Eng. Sanit. Ambient., 2010, 15 (4): 367-374.

BRAGA, A. C. O. Geofísica Aplicada: métodos geoelétricos em hidrogeologia. São Paulo, Oficina de Texto, 20016. 159 p.

BRAGA, A. C. O. Métodos Geoelétricos Aplicados nos Estudos de Captação e Contaminação das Águas Subterrâneas. 2007. Disponível em: http://www.rc.unesp.br/igce/aplicada/geoeletricosV4.pdf. Acesso em: 12/03/2016.

CELERE, M. S.; OlIVEIRA, A. S.; TREVILATO, T. M. B.; SEGURA-MUÑOZ, S. I. Metais presentes no chorume coletado no aterro sanitário de Ribeirão Preto, São Paulo, Brasil, e sua relevância para saúde pública. Cad. Saúde Pública, 2007, 23 (4): 939-947.

CHRISTENSEN, T. H. L.; KJELDSEN, P.; NJERG, P. L.; JENSEN, D. L.; CHRISTENSEN J. B.; BAUN, A.; ALBRECHSTEN, H.; HERON, G. Biogeochemistry of landfill leachate plumes. Applied Geochemistry, 2001, 16 (7/8): 659-718.

COMPANHIA DE PESQUISAS DE RECURSOS MINERAIS (CPRM). Carta Geológica do Brasil ao Milionésimo: FOLHAS NA.20 Boa Vista e NB.20 Roraima. Brasília: CPRM, Escala: 1:1.000.000. 2004.

COMPANHIA DE PESQUISAS DE RECURSOS MINERAIS (CPRM). Saneamento básico da cidade de Caracaraí, Estado de Roraima. Rio de Janeiro, CPRM/Serviço Geológico do Brasil, 1998. 34 p.

ELIS, V.; ZUQUETTE, L. V. Caracterização geofísica de áreas utilizadas para disposição de resíduos sólidos urbanos. Revista Brasileira de Geociências, 2002, 32 (1): 119-134.

FALCÃO, M. T.; BUÁS, A. I. C.; PINHEIRO, M. N.; OLIVEIRA, S. K. S. Implicações ambientais decorrentes das atividades urbanas em uma microbacia no Município de Boa Vista-Roraima. Revista Geonorte, 2012, 3 (4): 199-207.

FRANCO, E. M. S.; DELÁRCO, J.; RIVETTI, M. Folha NA.20-Boa Vista e parte das Folhas NA.21-Tumucumaque, NB.21. In: BRASIL, DNPM. Projeto RADAMBRASIL. Folha NA.20Roraima E NB 21.21 II - Geomorfologia. RIO DE JANEIRO, 1975. (Levantamento de Recursos Minerais, 8). 1975.

FRASSON, A. R.; WATZLAWICK, L. F.; MADRUGA, P. R. A.; SCHOENINGER, E. R. Avaliação de áreas propicias a instalação de aterros sanitários utilizando técnicas de geoprocessamento em sistemas eletroquímicos. Revista Ciências Exatas e Naturais, 2001, 3 (1): 87-95. 
GAllaS, J. D. F.; TAIOLI, F.; SILVA, S. M. C. P. D.; COELHO, O. G. W.; PAIM, P. S. G. Contaminação por chorume e sua detecção por resistividade. Revista Brasileira de Geofísica, 2005, 23 (1): 51-59.

GOES, D. A contribuição do aterro sanitário de resíduos sólidos - um breve estudo de caso no aterro de Paulo Afonso, Ba. Revista Científica da FASETE, 2016, 1: 90-105.

GOLUEKE, C. G. Biological reation in solid waste recovery systems. Compost Science Journal of Waste Recycling Texas, 1974, 15 (3): 2-6.

KEAREY, P.; BROOKS, M.; HILL, I. Geofísica de Exploração. 1ª Ed.: Oficina de Texto, São Paulo, 2009. 438 p.

KELlER, G. V.; FRISCHKNECHT, F. C. Electrical Methods in Geophysical Prospecting. Oxford, Pergamon Press, 1977. 517 p.

LAUREANO, A. T. Estudos geofísicos no aterro sanitário de Cuiabá, MT. Cuiabá, Dissertação (Mestrado em Física e Meio Ambiente) - Programa de Pós-Graduação em Física e Meio Ambiente, Universidade Federal do Mato Grosso, 2007. 164 p.

LAGO, A. L.; ELIS, V. R.; GIACHETI, H. L. Aplicação integrada de métodos geofísicos em uma área de disposição de resíduos sólidos urbanos em Bauru-SP. Revista Brasileira de Geofísica, 2006, 24 (3): 357-374.

MOURA, H. P.; MALAGUTTI FILHO, W. Métodos de eletrorresistividade e de polarização induzida aplicados na área de disposição de resíduos urbanos: aterro controlado de Rio Claro-SP. Geociências, São Paulo, 2003, 22 (especial): 129-139.

MOURA, H. P.; OLIVEIRA, M. J.; SACASA, R. J. V.; ROSÁRIO, J. M. L.; MALAGUTTI FILHO, W.; SOUTO, F. A. F.; NERY, J. R. C. Emprego da sondagem elétrica vertical com o método da eletrorresistividade no estudo do lixão de Macapá-AP. Geociências, São Paulo, 2007, 26 (3): 279-286.

MUCELIN, C. A.; BELLINI, M. Lixo e impactos ambientais perceptíveis no ecossistema urbano. Sociedade \& Natureza, Uberlândia, 2008, 20 (1): 111-124.

ORELLANA, E. Prospeccion geoelétrica en corriente contínua. Madrid: Paraninfo, 1972. 523 p. PARASNIS, D. S. Geofisica minera. Ed. Paraninfo, Madrid, 1971. 375 p.

PORTELA, M. O.; RIBEIRO, J. C. J. Aterros sanitários: aspectos gerais e destino final dos resíduos. Revista de Direito Ambiental de Sociedade, 2014, 4 (1): 115-134.

SCACABAROSSI, H.; PÉRICO, E. Perspectivas e desafios da coleta seletiva na cidade de Boa Vista-RR, no contexto da política nacional de resíduos sólidos, lei federal $\mathrm{n}^{\mathrm{o}}$ 12.305/2010. Geografia (Londrina), 2014, 23 (2): 49-69.

SCHALCH, V. Análise comparativa do comportamento de dois aterros sanitários semelhantes e correlações dos parâmetros do processo de digestão anaeróbia. São Carlos, Tese de Doutorado - Escola de Engenharia de São Carlos, Universidade de São Paulo, 1992. 220 p. 
SILVA, R. F. DA.; CANÇADO, C. J.; LORANDI, R.; GALIANO, V. A.; MOREIRA, M. A. Aplicação metodológica para seleção de áreas para disposição de resíduos sólidos industriais cerâmicos. Estudo de caso: Porto Ferreira - SP. São Paulo, UNESP, Geociências, 2005, 24 (3): 305-317.

SOARES, T. F.; FEITOZA, L. M.; SOUZA, L. S. B. Aplicação do método da eletrorresistividade em área de antiga disposição de resíduos sólidos no município de Boa Vista-RR. In: 48o. Congresso Brasileiro de Geologia (as geotecnologias e o século XXI), Porto Alegre. Anais... 480. Congresso Brasileiro de Geologia, 2016.

SOUZA, L. S. B. Evidências tectônicas no leste da Ilha do Marajó: integração de dados morfoestruturais e geofísicos. São Paulo, Tese (Doutoramento em Geoquímica e Geotectônica). Instituto de Geociências, Universidade de São Paulo, 2010. 202 p.

SOUZA, L. S. B.; CARVALHO, F. W. S. Contextualização geológica da porção sudoeste do Sistema Aquífero Boa Vista, estado de Roraima, Brasil, a partir de sondagens elétricas verticais rasas. Bol. Mus. Para. Emílio Goeldi. Cienc. Nat., Belém, 2017, 12 (1): 91-107.

SOUZA, L. S. B.; PAZ, J. D. S. da. Geofísica ambiental pontual no Sistema Aquífero Boa Vista e Aterro Sanitário Municipal, Boa Vista - RR. In: Geocências de Roraima, EDUFRR (ed.), coleção Geociências, vol. 2, Boa Vista, 2015. p. 117-143.

SOUZA, L. S. B.; ROSSETTI, D. F.; ELIS, V. R. Neotectonics in Marajó Island, state of Pará (Brazil) revealed by vertical electric sounding integrated with remote sensing geological data. Anais da Academia Brasileira de Ciências, 2013, 85: 73-86. DOI: http://dx.doi.org/10.1590/S0001-37652013000100006.

TElFORD, W. M.; GELDART, L. P.; HERIFF, R. E. Applied geophysics. Sec. Edition, Cambridge, Cambridge University Press, 1990. 770 p.

\section{AGRADECIMENTOS}

Ao Instituto de Geociências da Universidade Federal do Amazonas, em nome do professor Dr. João S. Carvalho, por ceder o equipamento. À professora Ma. Lorena M. Feitoza, e aos graduandos, Alexandre Uchôa, Franklin W. S. Carvalho, Liuvanderson S. Araújo e Moisés A. C. Júnior, do curso de geologia, Universidade Federal de Roraima, pelo auxílio nas etapas de campo. E a prefeitura do município de Caracaraí/RR por permitir o acesso à área e aos relatórios.

Recebido em: 29/12/2017

Aceito para publicação em: 26/06/2018 